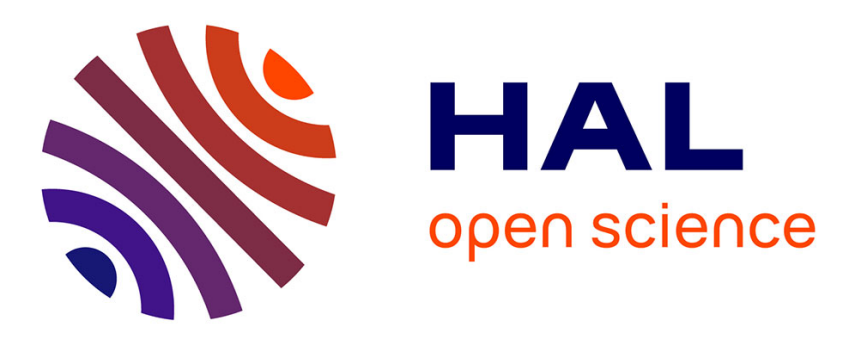

\title{
Studies of the molecular dynamics in polyurethane networks with hyperbranched crosslinkers of different coordination numbers
}

Przemyslaw Czech, Lidia Okrasa, Jacek Ulanski, Gisèle Boiteux, Françoise Méchin, Philippe Cassagnau

\section{To cite this version:}

Przemyslaw Czech, Lidia Okrasa, Jacek Ulanski, Gisèle Boiteux, Françoise Méchin, et al.. Studies of the molecular dynamics in polyurethane networks with hyperbranched crosslinkers of different coordination numbers. Journal of Applied Polymer Science, 2007, 105 (1), pp.89-98. 10.1002/app.26106 . hal-02046023

\section{HAL Id: hal-02046023 \\ https://hal.science/hal-02046023}

Submitted on 3 Apr 2019

HAL is a multi-disciplinary open access archive for the deposit and dissemination of scientific research documents, whether they are published or not. The documents may come from teaching and research institutions in France or abroad, or from public or private research centers.
L'archive ouverte pluridisciplinaire HAL, est destinée au dépôt et à la diffusion de documents scientifiques de niveau recherche, publiés ou non, émanant des établissements d'enseignement et de recherche français ou étrangers, des laboratoires publics ou privés. 


\section{Studies of the molecular dynamics in polyurethane networks with hyperbranched crosslinkers of different coordination numbers}

Przemyslaw Czech ${ }^{1,2}$, Lidia Okrasa ${ }^{1}$, Jacek Ulanski ${ }^{1}$, Gisele Boiteux ${ }^{2}$, Francoise Mechin $^{2}$, Philippe Cassagnau ${ }^{2}$

1. Department of Molecular Physics, Technical University of Lodz, 90-924 Lodz, Poland;

2. UMR CNRS 5627 "Ingénierie des Matériaux Polymères", Université Claude Bernard Lyon 1 and INSA-Lyon, Villeurbanne, France

Corresponding author: Lidia Okrasa, Fax: (+48 42) 63132 18; e-mail: lokrasa@ @.lodz.pl

Published in Journal of Applied Polymer Science vol. 105, 89-98 (2007)

Abstract: Several new polyurethane networks based on hyperbranched polyesters (trade name Boltorn ${ }^{\circledR}$ ) were synthesized to investigate the influence of the hyperbranched crosslinking agent on molecular dynamics of the linear segments containing urethane groups. For comparison, linear polyurethanes as well as polyurethanes crosslinked with the classical crosslinker trimethylolpropane were prepared. Broadband dielectric spectroscopy, dynamic mechanical analysis, and differential scanning calorimetry yielded consistent results concerning molecular relaxation processes; however dielectric spectroscopy appears to be more sensitive concerning the secondary relaxation processes. In the temperature range up to $150^{\circ} \mathrm{C}$, the molecular relaxations were very similar in all the investigated samples, despite considerable structural differences. The weak influence of the crosslinking on the molecular properties could be explained by the existence of hydrogen bonds forming a physical network, which was very dense in this temperature range in comparison with the chemical crosslinks and therefore dominated the molecular mobility in all the investigated systems. This hypothesis was confirmed by rheological measurements performed at temperatures above $150^{\circ} \mathrm{C}$, when the hydrogen bonds should be thermally destroyed. At these temperatures, the effect of crosslinking was manifested by a strong shift of the flowing point: in the linear 
polyurethanes, this point occurred at much higher frequencies (and lower temperatures) than in the crosslinked analogues.

Keywords: molecular dynamics, polyurethane networks, hyperbranched crosslinkers.

\section{INTRODUCTION}

Dendritic polymers are an intensively investigated class of macromolecular materials. Compared with dendrimers, hyperbranched (HB) polymers are less regular in their molecular structure, but they can be prepared by a single-step process avoiding complicated iterative reaction sequences and difficult purification. A lot of reviews dealing with the synthesis and properties of dendrimers and HB polymers have been published [1-5].

Dendritic polymers show unusual properties, in comparison with their linear analogues, resulting from their specific structure and numerous functional groups. Although $\mathrm{HB}$ macromolecules have a branching efficiency usually below $80 \%$, they possess many of the desirable properties for which dendrimers are noted. HB polymers have enormous potential for further reactions to give a wide variety of derivatives with unique properties, especially if alternative one-pot synthetic methods could be developed. Even if their utility value is restricted, they can be used in crosslinking processes or coating applications. A systematic investigation of HB polyesters as curing agents has been developed in Sweden [6,7].

Polyurethanes (PUs) are probably the most versatile class of polymers. PU elastomers are usually block copolymers, which consist of polyol sequences (soft segments) and diisocyanate/short diol sequences (hard segments). Most publications on this subject show that the composition and conditions of processing are the main factors that influence the chemical and morphological structure of the PUs and their properties [8-10].

In this work several PU networks based on HB crosslinkers were synthesized. The concentration of the crosslinking agent in the polymer mass and its coordination number were changed to obtain networks with different structures. The molecular dynamics of the obtained 
systems was investigated by means of dielectric relaxation spectroscopy (DRS), dynamic mechanical analysis (DMA), differential scanning calorimetry (DSC) and rheological measurements.

\section{EXPERIMENTAL}

\subsection{Materials}

Several PU networks crosslinked with HB polymers were synthesised in bulk with polytetrahydrofuran (Terathane ${ }^{\circledR} 650$ with $M_{n}=650 \mathrm{~g} / \mathrm{mole}$ ) and 4,4'-diisocyanatodiphenylmethane (MDI with $M_{w}=250 \mathrm{~g} / \mathrm{mole}$ ) as monomers and HB polyesters of $4^{\text {th }}$ and $3^{\text {rd }}$ generations (Boltorn ${ }^{\circledR} \mathrm{H} 40$ and Boltorn ${ }^{\circledR} \mathrm{H} 30$ ) and modified Boltorn ${ }^{\circledR} \mathrm{H} 40$ as crosslinking agents. Additionally, to check the influence of the crosslinking agent on the molecular dynamics, PU systems without a crosslinking agent or crosslinked with trimethylolpropane (TMP) were synthesized. Terathane 650, MDI and TMP were supplied by Sigma-Aldrich Co. (Poznan, Poland and Buchs, Switzerland). The Boltorn samples were produced by Perstorp Sweden Co. (Perstorp, Sweden). The structure of the different crosslinkers used in this study is shown in Fig.1. According to the producer, Boltorn ${ }^{\circledR} \mathrm{H} 40$ has a molar mass of $M_{w}=5100 \mathrm{~g} / \mathrm{mole}$, a polydispersity of $M_{w} / M_{n}=1.8$, and a hydroxyl number of 470-500 $\mathrm{mg} \mathrm{KOH} / \mathrm{g}$. These data give on average 44 primary -OH groups in the molecule. Boltorn ${ }^{\circledR} \mathrm{H} 30$ with a molar mass of $M_{w}=3500 \mathrm{~g} / \mathrm{mole}$, a polydispersity of $M_{w} / M_{n}=1.5$ and a hydroxyl number of $480-510 \mathrm{mg} \mathrm{KOH} / \mathrm{g}$ has on average 31 primary $-\mathrm{OH}$ groups in the molecule. The substrates were used as supplied by the producer without additional purification.

To reduce the number of primary $-\mathrm{OH}$ groups in the $4^{\text {th }}$ generation $\mathrm{HB}$ macromolecules, they were modified by p-tolylisocyanate (PTI). The schematic outline of the hyperbranched aliphatic polyester Boltorn ${ }^{\circledR} \mathrm{H} 40$ modification reaction is shown in Fig.2. Boltorn ${ }^{\circledR} \mathrm{H} 40$ was 
dissolved in tetrahydrofuran (THF) in a weight ratio of about $2: 1$ in a flask equipped with a magnetic stirrer. An appropriate amount of PTI needed to achieve the desired degree of blocking was added. The mixture was stirred at room temperature for 1 week. The completion of the reaction was determined by FTIR spectroscopy, when no peak connected with the presence of $-\mathrm{NCO}$ groups in the material was observed. In the second step, the reaction mixture was placed in a vacuum chamber at $60^{\circ} \mathrm{C}$ to remove THF. The evaporation was slow and regulated manually to avoid the rapid evacuation of THF and sloshing of the sample bulk. When a large majority of THF was removed, the material was placed in a vacuum drier. The modified Boltorn ${ }^{\circledR} \mathrm{H} 40$ was dried for 1 week under high vacuum at $60^{\circ} \mathrm{C}$. The residual amount of THF was checked by thermogravimetric analysis and taken into account for further calculations. The degree of modification of Boltorn ${ }^{\circledR} \mathrm{H} 40$ was calculated in accordance with the following equation:

$$
\mathrm{T}_{\mathrm{m}}=\frac{\mathrm{Eq}(\mathrm{OH})_{\mathrm{HBnmod}}-\mathrm{Eq}(\mathrm{OH})_{\mathrm{HBmod}}}{\mathrm{Eq}(\mathrm{OH})_{\mathrm{HBnmod}} \cdot\left[1+\mathrm{Eq}(\mathrm{OH})_{\mathrm{HBmod}} \cdot \mathrm{M}_{\mathrm{PTI}}\right]} \cdot 100 \%
$$

where: $\mathrm{Eq}(\mathrm{OH})_{\text {mod }}$ - number of - $\mathrm{OH}$ group moles per kilogram of modified Boltorn ${ }^{\circledR} \mathrm{H} 40$

$$
\mathrm{Eq}(\mathrm{OH})_{\mathrm{nmod}} \text { - number of -OH group moles per kilogram of unmodified Boltorn }{ }^{\circledR} \mathrm{H} 40
$$

$\mathrm{M}_{\mathrm{PTI}}$ - molar mass of PTI in $\mathrm{kg}$.

The number of moles of $-\mathrm{OH}$ groups in modified and unmodified Boltorn ${ }^{\circledR}$ materials was determined with $\mathrm{pH}$-metric titration. About 0.5 grams of the Boltorn ${ }^{\circledR}$ sample was dissolved in $10 \mathrm{~mL}$ of THF. Tosyl isocyanate was added in excess to neutralize the $-\mathrm{OH}$ groups of Boltorn ${ }^{\circledR}$. Then, the dibutylamine was added in excess to neutralize the rest of the unreacted -NCO groups from tosyl isocyanate. The mixture was titrated by $1 \mathrm{~N} \mathrm{HCl}$. The end point was indicated when the $\mathrm{pH}$ of the solutions reached 3.8. The number of moles of $-\mathrm{OH}$ groups per kilogram $[\mathrm{Eq}(\mathrm{OH})]$ was calculated with the following equation: 
$\mathrm{Eq}(\mathrm{OH})=\frac{\mathrm{V}_{\mathrm{eq}}-\mathrm{V}_{0}}{\mathrm{~m}}$

where: $\mathrm{V}_{\mathrm{eq}}$ - number of $\mathrm{mL}$ of $\mathrm{HCl}$ when $\mathrm{pH}=3.8$ for a solution containing dissolved Boltorn $^{\circledR}$

$\mathrm{V}_{0}$ - number of $\mathrm{mL}$ of $\mathrm{HCl}$ when $\mathrm{pH}=3.8$ for a blank test

$\mathrm{m}$ - mass of dissolved Boltorn ${ }^{\circledR}$

$\mathrm{Eq}(\mathrm{OH})$ for unmodified Boltorn ${ }^{\circledR} \mathrm{H} 40$ is equal to $8.4 \mathrm{~mol}$ of $\mathrm{OH} / \mathrm{kg}$ and for Boltorn ${ }^{\circledR} \mathrm{H} 30$ is equal to $8.5 \mathrm{~mol}$ of $\mathrm{OH} / \mathrm{kg}$. These results confirm data given by the producer.

The main aim of the synthetic work presented in this article is to elaborate networks in which PU linear chains are connected by the HB crosslinkers with different coordination numbers. The number of primary $-\mathrm{OH}$ functions present in the $\mathrm{HB}$ polymer has to control in fact the number of the linear segments connected to the HB polyester. The linear chains in this network series have a constant length described by the number of macrodiol-diisocyanate repeating units $(n)$, equal to 4 . The synthesis of PUs was carried out in bulk. A schematic route for the synthesis of the PU networks crosslinked with HB centres is shown in Fig.3. The amounts of the ingredients for the synthesis of the stoichiometric systems were calculated in accordance with the number of $-\mathrm{OH}$ groups in the crosslinker and the projected length (in this case, $n=4$ ) of the linear segments between the crosslinking centres [11]. The calculated amount of Terathane ${ }^{\circledR}$ was placed in a flask equipped with magnetic stirrer, heated up to $80^{\circ} \mathrm{C}$, and kept ther for half an hour in vacuo. Then, the crosslinker was added, and the mixture was stirred at about $100^{\circ} \mathrm{C}$ until the complete dissolution of the reactants. When the solution was clear, it was degassed in vacuo at $60^{\circ} \mathrm{C}$ for half an hour to avoid bubbling during the reaction. In the next step, MDI, preheated up to $60^{\circ} \mathrm{C}$, was added. After quick mixing for about $1 \mathrm{~min}$, the reactive solution was cast onto an aluminium pan and again placed in vacuo at $60^{\circ} \mathrm{C}$ for half an hour. To get the full conversion of the reactive system, the pan was placed in the 
drying oven at $100^{\circ} \mathrm{C}$ for $7 \mathrm{~h}$. The polymers were obtained as films with thicknesses ranging from 0.2 to $1 \mathrm{~mm}$. The end of the reaction was determined by FTIR spectroscopy. In the PU networks, the diisocyanate $-\mathrm{N}=\mathrm{C}=\mathrm{O}$ band $\left(2250-2275 \mathrm{~cm}^{-1}\right)$ was absent in the spectra. The bands characteristic of the urethane bonds could be observed at: $3320 \mathrm{~cm}^{-1}$ - the urethane N$\mathrm{H}$ stretching; $1731 \mathrm{~cm}^{-1}$ - the urethane $\mathrm{C}=\mathrm{O}$ without hydrogen bonding; $1710 \mathrm{~cm}^{-1}$ - urethane $\mathrm{C}=\mathrm{O}$ with hydrogen bonding; $1535 \mathrm{~cm}^{-1}$ - urethane $\mathrm{C}-\mathrm{N}-\mathrm{H}$ bonding.

\subsection{Characterization techniques.}

The chemical structure of the synthesized materials was verified by FTIR absorption with a Bio-Rad FTS $175 \mathrm{C}$ spectrometer (Krefeld, Germany) in the reflection mode with a Harrick IRS (Krefeld, Germany) attachment.

The glass transition temperatures $(T g)$ were determined by DSC (TA Instrument DSC 2920) with samples of about $10 \mathrm{mg}$ in sealed aluminium pans. Two runs were performed for each sample in the range from $-150^{\circ} \mathrm{C}$ to $+200^{\circ} \mathrm{C}$ at a heating rate of $10 / \mathrm{min}$ under a nitrogen atmosphere. The cooling scans were performed at an average rate of $25 / \mathrm{min}$. The $T g$ values were determined as the onset points from the second scan.

Molecular relaxations were characterised in broad temperature and frequency ranges by DMA with a TA Instrument DMA 2980 Dynamic Mechanical Analyser, and by DRS with a Novocontrol (Hundsangen, Germany) Broadband Dielectric Spectrometer. DMA was performed in film tension mode in the temperature range from -130 up to $+150^{\circ} \mathrm{C}$ with a temperature ramp of $2 / \mathrm{min}$ on rectangular samples with a length of $25 \mathrm{~mm}$, a width of $5 \mathrm{~mm}$, and a thickness of $1 \mathrm{~mm}$. Three frequencies were applied: 1, 5, and $10 \mathrm{~Hz}$. DRS was performed in the frequency range of $0.01 \mathrm{~Hz}$ to $1 \mathrm{MHz}$ and in the temperature range from -150 up to $+130^{\circ} \mathrm{C}$ in $5^{\circ} \mathrm{C}$ steps. For these measurements, circular samples with a diameter of $20 \mathrm{~mm}$ and a thickness up to $0.5 \mathrm{~mm}$ were used. 
Dielectric results were presented in the classical representation of the dielectric permittivity $\left(\varepsilon^{*}=\mathcal{E}^{\prime}+\mathrm{i} \mathcal{E}^{\prime}\right.$, where $\mathcal{E}^{\prime}$ and $\mathcal{E}^{\prime \prime}$ are the real and imaginary parts of the permittivity, respectively), and with the electric modulus $\left(M^{*}=M^{\prime}+\mathrm{i} M^{\prime \prime}\right.$, where $M^{\prime}$ and $M^{\prime \prime}$ are the real and imaginary parts of the electric modulus, respectively) representation defined by Macedo et al. [12]. $M^{\prime}$ and $M$ " were calculated according to the following equations:

$$
\begin{aligned}
& M^{\prime}=\frac{\varepsilon^{\prime}}{\varepsilon^{\prime 2}+\varepsilon^{\prime 2}} \\
& M^{\prime \prime}=\frac{\varepsilon^{\prime \prime}}{\varepsilon^{\prime 2}+\varepsilon^{\prime 2}}
\end{aligned}
$$

Although the permittivity representation is easier to interpret, the modulus representation can be very useful when conductivity processes are involved.

The relaxation maps were prepared on the basis of both dielectric and mechanical spectra. The points were taken from the $\varepsilon^{\prime \prime}(f)$ plots using the WinFit software (Novocontrol, Hundsangen, Germany) for dielectric relaxations and for conductivity phenomenon manually from the $M$ " $(T)$ plots. For the mechanical relaxations, the points from the loss modulus, $E$ ” $(T)$ plots were taken. The relaxation times $(\tau)$ were calculated with the following equation: $\tau=1 /(2 \pi f)$, where $f$ stands for the frequency.

Linear viscoelastic measurements of the complex shear modulus $\left(G^{*}(\omega)=G^{\prime}(\omega)+G^{\prime \prime}(\omega)\right.$, where $G^{\prime}$ is real part and $G^{\prime \prime}$ is imaginary part of shear modulus) were performed with a Rheometrics Instrument RS5 apparatus (Prinstown, USA) in the range of temperatures from +150 up to $+230^{\circ} \mathrm{C}$ and for frequencies from $10^{-2}$ up to $10^{2} \mathrm{rad} / \mathrm{s}$. The temperature step was 10 . Samples for these measurements had a diameter of $25 \mathrm{~mm}$ and a thickness of about $0.5 \mathrm{~mm}$. Nitrogen was used to prevent thermal oxidation. 


\section{RESULTS}

The glass transition temperatures of the investigated systems determined by means of DSC are collected in Table 1. The differences in the Tgs of the PU networks are not large, but a clear tendency can be observed: $T g$ increases with decreasing coordination number of the crosslinker.

Fig.4 shows the three-dimensional frequency and temperature dependence of $\mathcal{E}$ " for the PU network crosslinked by unmodified Boltorn ${ }^{\circledR} \mathrm{H} 40$ and for the noncrosslinked PU. On the DRS spectra, we can see three relaxation processes named $\alpha, \beta$ and $\gamma$ relaxations in order of decreasing temperature. In the highest temperature range, above the $\alpha$ relaxation, the conductivity phenomenon occurs. The conductivity phenomenon gives on the diagram of the electrical modulus representation (see Fig.5) one more maximum above the $\alpha$ peak. These relaxation processes can be seen in all the investigated samples, although the $\beta$ relaxation is well pronounced only in the networks crosslinked by the HB crosslinkers.

Fig.5 shows DRS and DMA spectra for the sample crosslinked by unmodified Boltorn ${ }^{\circledR} \mathrm{H} 40$ in comparison with the sample crosslinked by the classical crosslinker, TMP, and with the noncrosslinked sample. One can see that the position of the $\alpha$-relaxation maximum related to $T g$ depends very weakly only on the kind of crosslinker. At $1 \mathrm{~Hz}$, the maximum of the $\alpha$-relaxation peak is at about $-22^{\circ} \mathrm{C}$ for the sample crosslinked by Boltorn ${ }^{\circledR} \mathrm{H} 40$, at $-16^{\circ} \mathrm{C}$ for the sample crosslinked by TMP, and at about $-18^{\circ} \mathrm{C}$ for the noncrosslinked PU. This tendency correlates well with the DSC data shown in Table 1. The intensity of these $\alpha$ peaks is almost equal; only for the samples with Boltorn ${ }^{\circledR} \mathrm{H} 40$, it is slightly lower. As was mentioned previously, the $\beta$ relaxation is well pronounced only for the sample crosslinked with the HB polymer. The temperature position of this peak for a frequency of $1 \mathrm{~Hz}$ is about $-85^{\circ} \mathrm{C}$. The activation energy $\left(E_{a}\right)$ of the $\beta$ relaxation is about $63 \pm$ $1 \mathrm{~kJ} / \mathrm{mol}$. For other samples, this peak is weak, and its exact temperature position was difficult 
to determine. For all the systems, the $\gamma$ relaxation is quite visible, and although the differences in its peak position are small, there are noticeable differences in the $E_{a}$ values. For the noncrosslinked PU, $E_{a}$ is $38.2 \pm 0.2 \mathrm{~kJ} / \mathrm{mol}$, whereas $E_{a}$ is $39.8 \pm 0.5$ and $44.8 \pm 0.5 \mathrm{~kJ} / \mathrm{mol}$ for the network systems crosslinked by Boltorn ${ }^{\circledR} \mathrm{H} 40$ and TMP, respectively. The DMA investigations give similar results, but the $\gamma$ relaxation is beyond the investigation ranges of the frequency and temperature. All points from dielectric and mechanical results are collected on the activation plot shown in Fig.6.

In Fig.7, the results of the rheological measurements at high temperatures for these three samples are shown. As expected, it can be seen that the linear sample differs strongly from the crosslinked samples. The linear sample behaves as a viscoelastic liquid, whereas the crosslinked samples behave as viscoelastic solids. However, this viscoelastic solid behaviour is observed only at a high frequency, as the onset of the terminal relaxation zone can be easily seen in this figure. The observation of this relaxation zone, or flowing zone, is rather unexpected for crosslinked systems because an elastic temporary network is pointed out. This can be explained by the fact that the density of the chemical crosslinking is very low; therefore, in these crosslinked systems, it is possible to observe the flowing behaviour. In addition, it is also clear from Fig.8, showing the variation of the complex shear modulus versus the frequency for PU-HB4-22 at different temperatures, that the time-temperature superposition cannot be applied in the entire range of investigated temperatures $\left(150^{\circ} \mathrm{C}<T<230^{\circ} \mathrm{C}\right)$. Only for temperatures higher than about $180^{\circ} \mathrm{C}$ can this principle be applied within the experimental error. Actually, this result shows that the nature of the interchain interactions, hydrogen bonding, drastically changes at temperatures close to $180^{\circ} \mathrm{C}$. At much higher temperatures, above about $220^{\circ} \mathrm{C}$, the time-temperature superposition principle also cannot be applied, presumably because of the beginning of the thermal degradation of the PU. 
The onset of the terminal relaxation zone $\left(\omega_{\mathrm{G}^{\prime}=\mathrm{G}^{\prime}}\right)$ was used to define the onset of the flowing behaviour and is named the flowing point in this article. As expected, the flowing points for the noncrosslinked PU are higher than those for the crosslinked samples. For usual crosslinked polymers, the flowing point tends to zero (permanent elasticity) above the gel point. Nevertheless, it can be seen from the inset figure in Fig.7 that the results obey the same Arrhenius plot; that is, this phenomenon has the same activation energy. This result means that the hydrogen interactions change with the temperature in the same way for noncrosslinked and crosslinked PU.

Boltorn ${ }^{\circledR} \mathrm{H} 40$ was used as a crosslinker in an unmodified form and with partial modification of the terminal $-\mathrm{OH}$ groups. Fig.9 shows the dielectric and mechanical spectra of the PU systems crosslinked by Boltorn ${ }^{\circledR} \mathrm{H} 40$ crosslinkers with different coordination numbers, and Fig.10 shows the relaxation map collecting all the points from the DRS and DMA maxima. On the dielectric spectra, three relaxation processes and conductivity are visible. The $\alpha$ relaxation connected with $T g$ depends on the functionality of the $\mathrm{HB}$ crosslinker: the more $-\mathrm{OH}$ groups are present in the crosslinking agent, the lower the temperatures are of the $\alpha$ relaxation in the network. This effect is observed also in the DMA and DSC results. The $\beta$ relaxation is well pronounced for all the samples, except the one crosslinked by Boltorn $^{\circledR}$ with the lowest coordination number (PU-HB4-59). $E_{a}$ of the $\beta$ relaxation is similar for all the samples and equals about $62-64 \mathrm{~kJ} / \mathrm{mol}$. Also, the $\gamma$ relaxation does not differ very much with changing crosslinker functionality and appears at about $-140^{\circ} \mathrm{C}$ at $1 \mathrm{~Hz}$. Its $E_{a}$ is about $36-39 \mathrm{~kJ} / \mathrm{mol}$, but the changes are not regular. DMA gives coherent results with the DRS investigations.

The rheological data for the networks based on Boltorn ${ }^{\circledR} \mathrm{H} 40$ with different modification degrees are shown in Fig.11. One can see that for this series of samples, the flowing points 
differ only slightly. This is caused by the fact that the density of the chemical crosslinking in these networks is similar.

Finally, the influence of the crosslinker generation on the molecular dynamics was investigated. In Fig.12a, a comparison of the DRS and the DMA spectra for the samples crosslinked by Boltorn ${ }^{\circledR} \mathrm{H} 40$ and Boltorn ${ }^{\circledR} \mathrm{H} 30$ is shown. Fig.13 shows the activation plot made on the basis of these spectra. Also, for PU-HB3-0, the dielectric spectra show three relaxation processes and the conductivity phenomenon at high temperatures. In DRS, for sample PU-HB3-0, the $\alpha$ relaxation is shifted to lower temperatures in comparison with PU-HB4-0. The $\beta$ process in the PU-HB3-0 has a higher activation energy, about $81 \mathrm{~kJ} / \mathrm{mol}$, whereas for PU-HB4-0, it is only $63 \pm 1 \mathrm{~kJ} / \mathrm{mol}$. The $\gamma$ relaxation is practically identical in both samples.

The variation of the complex shear modulus for PU-HB4-0 and PU-HB3-0 is shown in Fig. 14 at $\mathrm{T}=200^{\circ} \mathrm{C}$. It can be observed that the flowing points are nearly the same for these two samples. However, the magnitude of the temporary elastic modulus is quite different. Interestingly, the sample with the fourth generation crosslinking agent has a lower temporary elastic modulus than the sample with the third generation of the crosslinking agent.

\section{DISCUSSION}

In all the investigated systems, three relaxation processes (primary $\alpha$ and secondary $\beta$ and $\gamma$ ) can be observed with DRS and DMA. In the linear viscoelastic investigations at high temperatures, a characteristic flowing point, $\omega_{\mathrm{G}^{\prime}=\mathrm{G}^{\prime}}$, was determined at lower frequencies. All these molecular processes are more or less sensitive upon the crosslinking of the PU macromolecules.

The primary $\alpha$ relaxation, associated with the glass transition process, is observed by means of both DRS and DMA. These techniques give coherent results confirmed by the DSC 
measurements. The introduced crosslinking agent has only a weak influence on the glass transition ( $\operatorname{Tg}$ shifts by less than $5^{\circ} \mathrm{C}$ - see table 1$)$. The $\alpha$ relaxation is well pronounced for all the crosslinked systems, and the position of the peak is shifting only slightly to a higher temperature with decreasing crosslinker functionality. Such behaviour was expected because the crosslinker concentration in our systems can only slightly influence the flexibility of the linear chains between the crosslinking points, and it is mobility of the large segments of these chains that determines the position of the $\alpha$ relaxation and the glass transition. Additionally, one can argue that the hydrogen bonds, which are created between urethane groups in the linear chains, form at low temperatures similar physical networks in all these systems. The density of the H-bonds is much higher than the density of the chemical crosslinking points in the network, so at temperatures below and near the glass transition, the H-bonds play a dominant role. Similar findings of dominating effects of the hydrogen bonds in HB polyurea/urethane systems on their properties are described in an article by Abd Elrehim et al [13]. Also Sheth et al has underlined the role of the distribution of hydrogen bonding in the properties of highly branched, segmented poly(urethane urea) copolymers [14].

The secondary $\beta$ relaxation is most likely attributable to the local motions of the polar urethane groups $[10,15,16]$. Although all the samples show the $\beta$ relaxation in a similar temperature region, one can see that the $\beta$ peak is well pronounced only for the samples crosslinked with the HB polymers of a high coordination number. For the rest of the samples, this process is only slightly marked, and its detailed analysis is very difficult, sometimes even impossible. Such differences in the intensity of the $\beta$ relaxation can be explained by differences in the ease of creation of H-bonds between the urethane groups. In the linear systems or systems crosslinked by relatively small TMP molecules, the $\beta$ relaxation is almost invisible because most of the urethane groups are fixed by hydrogen bonds. The possibility of H-bonds creation between urethanes is lower in the samples with Boltorn ${ }^{\circledR}$. The HB molecule 
has a diameter comparable to the length of the linear segments. Because of such an architecture, one can expect that the linear chains will be more separated and create weaker H-bonds. Additionally, the urethane groups connected directly to the HB crosslinkers do not form H-bonds at all because of steric hindrance and can move relatively easily. Therefore, more urethane groups are mobile and can contribute in this case to the $\beta$ relaxation. In the system crosslinked by Boltorn ${ }^{\circledR} \mathrm{H} 30$ or Boltorn ${ }^{\circledR} \mathrm{H} 40$ with a high modification degree, the $\beta$-relaxation process is less pronounced because such nonbonded urethane groups are less numerous there.

The $\gamma$ relaxation visible in all the examined systems is associated with a local motion of the $\left(\mathrm{CH}_{2}\right)_{4}$ sequences of the soft segments. Because in the investigated systems such sequences are almost identical, no significant differences are observed in the behaviour of this relaxation.

To verify the hypothesis that strong H-bonds are present in the systems and that the physical network determines the material properties, high-temperature rheological measurements were performed. At temperatures above about $180^{\circ} \mathrm{C}$, the hydrogen bonds should be thermally destroyed, and the chemical nature of the networks should be visible. On the rheological plots, one can see that the flowing point for linear PU is detected at a much higher frequency and lower temperature range than for the chemically crosslinked samples, and this results from the higher mobility of the noncrosslinked chains. Surprisingly enough, a non-permanent elasticity of the crosslinked sample was observed. This strange behaviour can be explained by the very low density of the chemical crosslinking. However, all networks show similar flowing behaviour in rheological investigations. This is caused by the fact that the density of crosslinking of these networks is the same (the same length of linear chains between crosslinking points). 


\section{CONCLUSION}

It has been found that the molecular dynamics in new PU networks based on HB polyesters are weakly dependent on the network architecture. Unexpected small differences observed between the noncrosslinked and crosslinked samples have been explained by the presence of the physical network. Only at high enough temperatures, when the H-bonds can be broken, can the differences in the molecular mobility easily be seen in the rheological properties. An unexpected result has been observed because the crosslinked samples exhibit at a low frequency the onset of a flowing zone (relaxation zone). However, as expected, the flowing point for linear PU is at a much higher frequency (or at a lower temperature) than that for the crosslinked samples.

At lower temperatures, a change in the crosslinking agent nature results in a relatively weak modification of the $\alpha$ relaxations. This is explained by the fact that the dynamics of the PU chains are quite similar in the different systems as they depend mainly on the physical network created by hydrogen bonds taking place between the urethane groups of the chains, this physical network being nearly the same in all cases. Among the secondary relaxations, only $\beta$ relaxations show some sensitivity to the presence of the crosslinker. The intensity of the $\beta$ relaxation depends on the kind of the crosslinker, and this process is quite visible only in the samples with the HB crosslinkers. This is because the urethane groups, which are close to the HB crosslinker have lower probability to create the H-bonds between them, so more urethane groups are mobile and can contribute to the $\beta$ relaxations.

\section{ACKNOWLEDGEMENTS}

This work was supported partially by MIRA project $\mathrm{N}^{\mathrm{o}} 0200665901$ (Rhone-Alpes, France), by KBN project N 4 T08E 01223 (Poland), and by Department of Molecular Physics of Technical University of Lodz (Poland) and Laboratory of Polymer Materials and 
Biomaterials of University Lyon 1 (France) in a frame of NoE "NANOFUN-POLY" 6FP EU.

We would like to express our special gratitude to the late Professor Tadeusz Pakula for many fruitful discussions and inspiring suggestions.

This paper is dedicated to the memory of Professor Marian Kryszewski, founder of the Polish School of Polymer Physics and promoter of Polish-French scientific collaboration.

\section{REFERENCES}

1. Tomalia, D. A.; Naylor, A. M.; Goddard, W. A. Angew Chem Int Ed Engl 1990, 29, 138.

2. Newkome, G. R.; Moorfield, C. N.; Vogtle, F. Dendritic macromolecules: concept synthesis perspectives, Weinheim: VCH, 1996.

3. Zeng, F.; Zimmerman, S. C. Chem Rev 1997, 97, 1681.

4. Kim, Y. H. J Polym Sci, Part A: Polym Chem 1998, 36, 1685.

5. Kim, Y. H.; Webster, O.W. In: Star and hyperbranched polymers, Mishra, M. K.;

Kobayashi, S., Ed.; Mercel Dekker INC: New York, 1999, 201.

6. Johansson, M.; Hult, A. J Coat Technol 1995, 667, 35.

7. Hult, A.; Johansson, M.; Malmstrom, E. Macromol Symp 1995, 98, 1159.

8. Mitzner, E.; Goering, H.; Becker, H. R. Angew Macromol Chem 1994, 220, 177.

9. Dabdin, S.; Burford, R. P.; Chaplin, R. P. Polymer 1996, 37,785-792.

10. Knapitsas, A. ; Pissis, P. ; Garcia Estrella, A. Eur Polym J 1999, 35, 923.

11. Czech, P.; Okrasa, L.; Boiteux, G.; Mechin, F.; Ulanski, J. J Non-Cryst Sol 2005, 351, 2753.

12. Macedo, P. B.; Moynihan, C. T.; Bose, R. Phys Chem Glasses 1972, 13, 171.

13. Abd Elrehim, M.; Voit, B.; Bruchmann, B.; Eichhorn,K.-J.; Grundke, K.; Bellmann, C. J Polym Sci, Part A: Polym Chem 2005, 43, 3376-3393. 
14. Sheth, J. P.; Unalb, S.; Yilgorc, E.; Yilgorc, I.; Beyerd, F. L.; Longb, T. E.; Wilkes, G. L. Polymer 2005, 46, 10180-10190.

15. Kanapitsas, A.; Pissis, P.; Gomez Ribelles, J. L.; Monleon Pradas, M.; Privalko, E. G.;

Privalko, V. P. J Appl Polym Sci 1999, 71, 1209.

16. Apekis, L.; Pissis, P.; Christodoulides, C.; Spathis, G.; Nisounakis, M.; Kontou, E.;

Schlosser, E.; Schoenhals, A.; Goering, H. Colloid Polym Sci 1992, 90, 144. 
Table 1. Glass transition temperatures for the PU based systems determined from DSC.

\begin{tabular}{|c|c|c|}
\hline Sample & Type of crosslinking agent & $\operatorname{Tg}\left[{ }^{\circ} \mathrm{C}\right]$ \\
\hline $\mathrm{PU}$ & - & -37.3 \\
\hline PU-TMP & TMP & -32.7 \\
\hline PU-HB4-59 & $\begin{array}{c}\text { Boltorn }{ }^{\circledR} \mathrm{H} 40 \\
59 \% \text { of }-\mathrm{OH} \text { blocked }\end{array}$ & -33.1 \\
\hline PU-HB4-22 & $\begin{array}{c}\text { Boltorn }{ }^{\circledR} \mathrm{H} 40 \\
22 \% \text { of }-\mathrm{OH} \text { blocked }\end{array}$ & -35.8 \\
\hline PU-HB4-14 & $\begin{array}{c}\text { Boltorn }{ }^{\circledR} \mathrm{H} 40 \\
14 \% \text { of }-\mathrm{OH} \text { blocked }\end{array}$ & -37.2 \\
\hline PU-HB4-0 & $\begin{array}{l}\text { Boltorn }{ }^{\circledR} \mathrm{H} 40 \\
\text { non-modified }\end{array}$ & -39.3 \\
\hline PU-HB3-0 & $\begin{array}{l}\text { Boltorn }{ }^{\circledR} \mathrm{H} 30 \\
\text { non-modified }\end{array}$ & -35.1 \\
\hline
\end{tabular}




\section{Figure captions}

Fig. 1. Simplified chemical structures of the crosslinking agents used in the reaction.

Fig. 2. Schematic reaction of Boltorn ${ }^{\circledR} \mathrm{H} 40$ modification with the monoisocyanate.

Fig. 3. Diagram of the PU network synthesis.

Fig. 4. Frequency and temperature dependence of the imaginary part of the permittivity for: (a) network PU-HB4-0 and (b) noncrosslinked PU.

Fig. 5. DMA and DRS spectra for the non-crosslinked PU $(\boldsymbol{\square}, \square)$ and the networks: PU-TMP $(\bullet, O)$ and PU-HB4-0 $(\boldsymbol{\Delta}, \triangle)$. The full points represent the real part of the moduli, and the open points represent the imaginary part.

Fig. 6. Relaxation map for the noncrosslinked PU $(\boldsymbol{\square}, \square)$ and the networks: PU-TMP $(\bullet, \bigcirc)$ and PU-HB4-0 $(\boldsymbol{\Delta}, \triangle)$. The open points represent DRS, and the full points represent DMA.

Fig. 7. Variation of the complex shear modulus versus the frequency for the non-crosslinked PU $(\boldsymbol{\square}, \square)$ and the networks: $\operatorname{PU}-\mathrm{TMP}(\bullet, \bigcirc)$ and $\operatorname{PU}-H B 4-0(\boldsymbol{\Delta}, \triangle)$. The full points represent the storage modulus, and the open points represent the loss modulus. The inset diagram shows the Arrhenius plot for the flowing points.

Fig. 8. Variation of the shear complex modulus versus frequency for PU-HB4-22 at different temperatures: $150^{\circ} \mathrm{C}(\boldsymbol{\square}, \square), 170^{\circ} \mathrm{C}(\bullet, \bigcirc), 180^{\circ} \mathrm{C}(\boldsymbol{\Delta}, \triangle), 190^{\circ} \mathrm{C}(\boldsymbol{\nabla}, \nabla), 200^{\circ} \mathrm{C}(\bullet, \diamond)$, $210^{\circ} \mathrm{C}(\varangle, \triangleleft), 220^{\circ} \mathrm{C}(\triangleright, \nabla)$, and $230^{\circ} \mathrm{C}(\star, \downarrow)$. The full points represent the storage modulus, and the open points represent the loss modulus.

Fig. 9. DMA and DRS spectra for the samples crosslinked by Boltorn ${ }^{\circledR} \mathrm{H} 40$ with different coordination numbers: PU-HB4-0 $(\boldsymbol{\Delta}, \triangle)$, PU-HB4-14 $(\boldsymbol{\nabla}, \nabla), \quad$ PU-HB4-22 $(\bullet, \diamond)$, 
PU-HB4-59 $(\bullet, 0)$. The full points represent the real part of the moduli, and the open points represent the imaginary part.

Fig. 10. Relaxation map for samples crosslinked by Boltorn ${ }^{\circledR} \mathrm{H} 40$ with different coordination numbers: PU-HB4-0 $(\boldsymbol{\Delta}, \triangle)$, PU-HB4-14 $(\boldsymbol{\nabla}, \nabla)$, PU-HB4-22 $(\bullet, \diamond)$, PU-HB4-59 $(\bullet, \bigcirc)$. The open points represent DRS, and the full points represent DMA.

Fig. 11. Variation of the complex shear modulus versus the frequency for the samples crosslinked by Boltorn ${ }^{\circledR} \mathrm{H} 40$ with different coordination numbers: PU-HB4-0 $(\boldsymbol{\Delta}, \triangle)$, PU-HB4-14 $(\boldsymbol{\nabla}, \nabla)$, PU-HB4-22 $(\bullet, \diamond)$, PU-HB4-59 $(\bullet, \bigcirc)$. The full points represent the storage modulus, and the open points represent the loss modulus. Insert diagram shows the Arrhenius plot for the flowing points.

Fig. 12. DMA and DRS spectra for the samples crosslinked by Boltorn ${ }^{\circledR}$ with different generations: PU-HB4-0 $(\boldsymbol{\Lambda}, \triangle)$ and PU-HB3-0 $(\boldsymbol{\square}, \square)$. The full points represent the real part of the moduli, and the open points represent the imaginary part.

Fig. 13. Relaxation map for the samples crosslinked by Boltorn ${ }^{\circledR}$ with different generations: PU-HB4-0 $(\boldsymbol{\Delta}, \triangle)$ and PU-HB3-0 $(\boldsymbol{\square}, \square)$. The open points represent DRS, and the full points represent DMA.

Fig. 14. Variation of the complex shear modulus versus the frequency for the samples crosslinked by Boltorn ${ }^{\circledR}$ with different generations: PU-HB4-0 $(\boldsymbol{\Lambda}, \triangle)$ and PU-HB3-0 $(\boldsymbol{\square}, \square)$. The full points represent the storage modulus, and the open points represent loss modulus. The inset diagram shows the Arrhenius plot for the flowing points. 

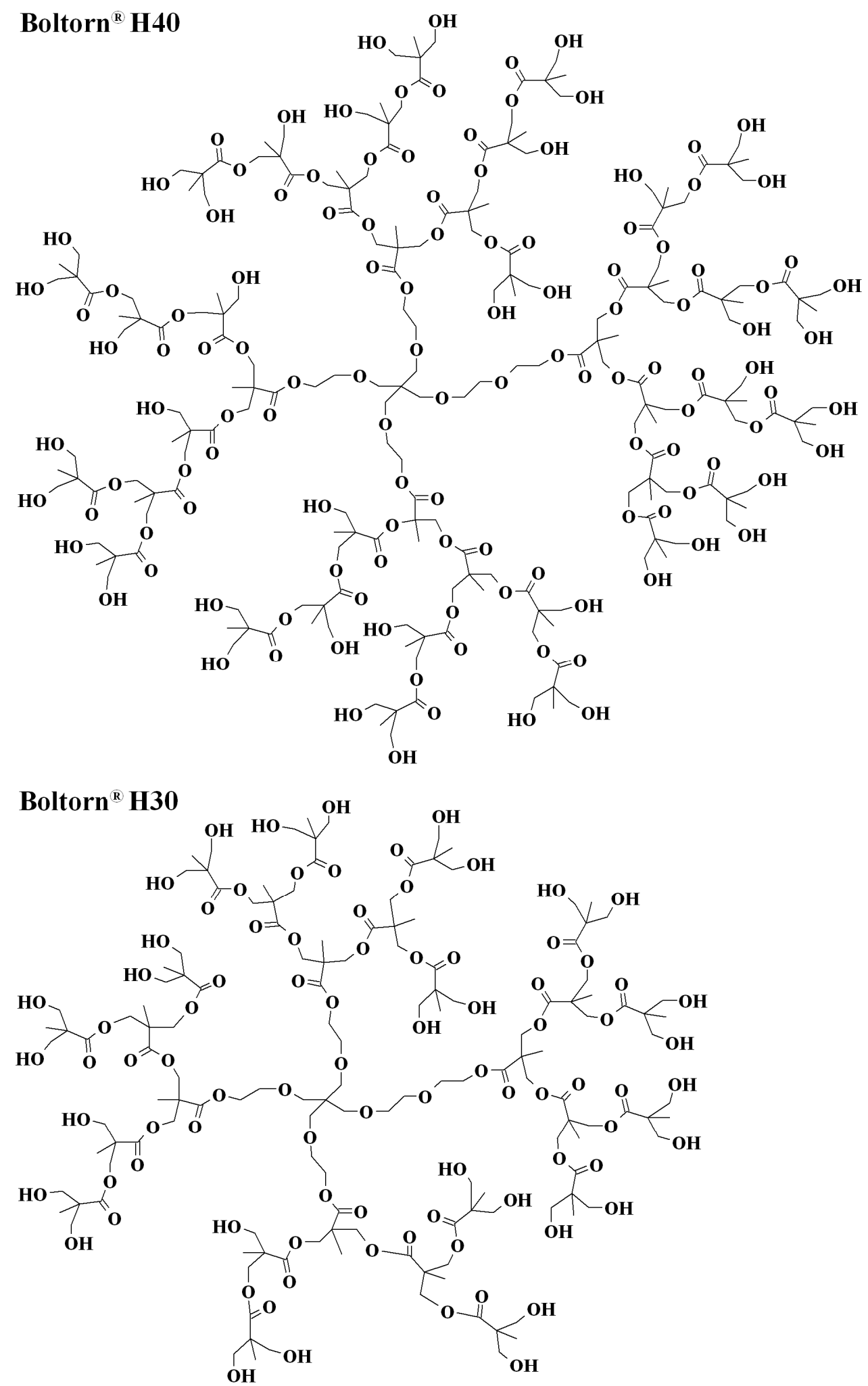

TMP<smiles>CCC(CO)(CO)CO</smiles>

Figure 1 

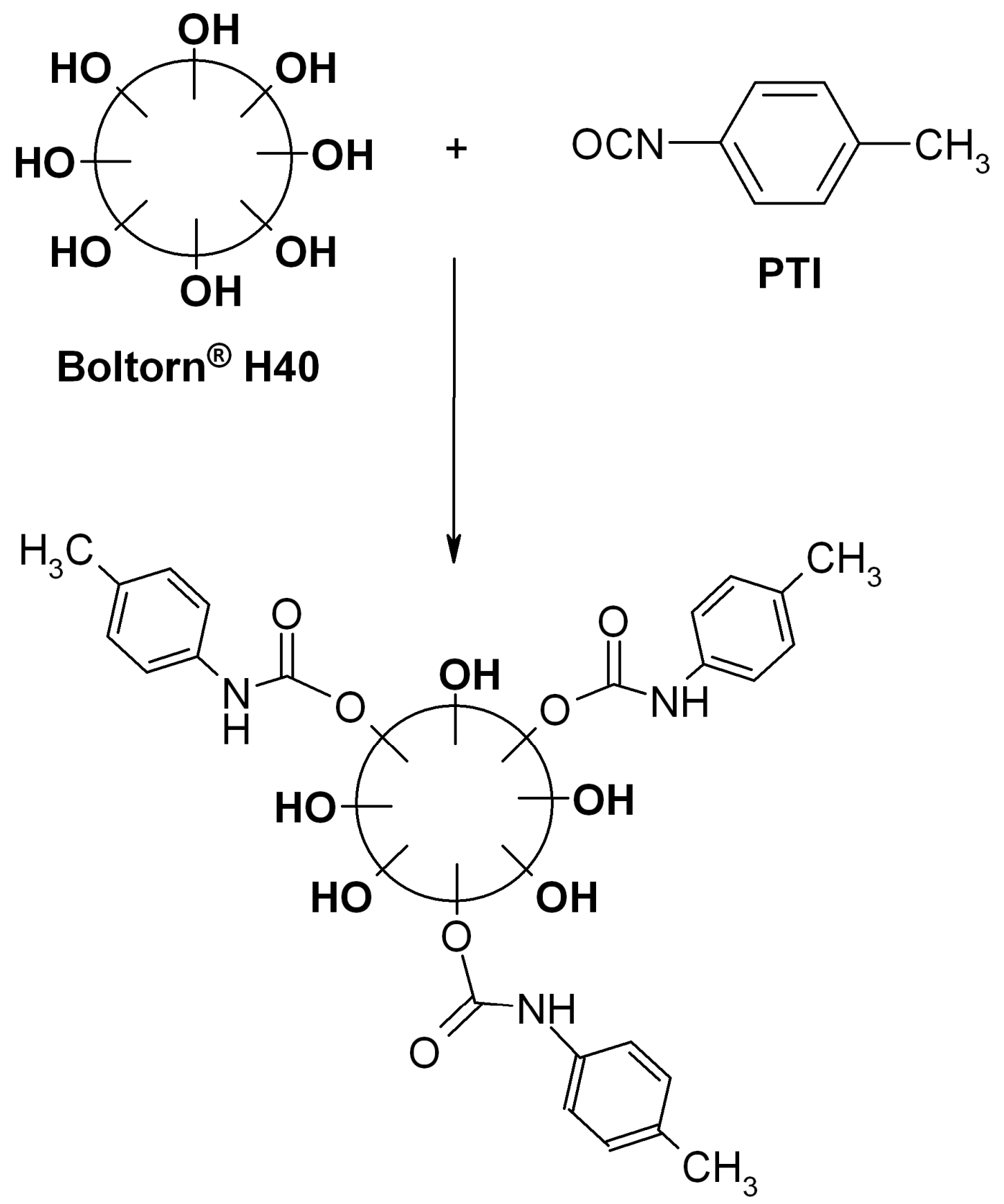

Figure 2 


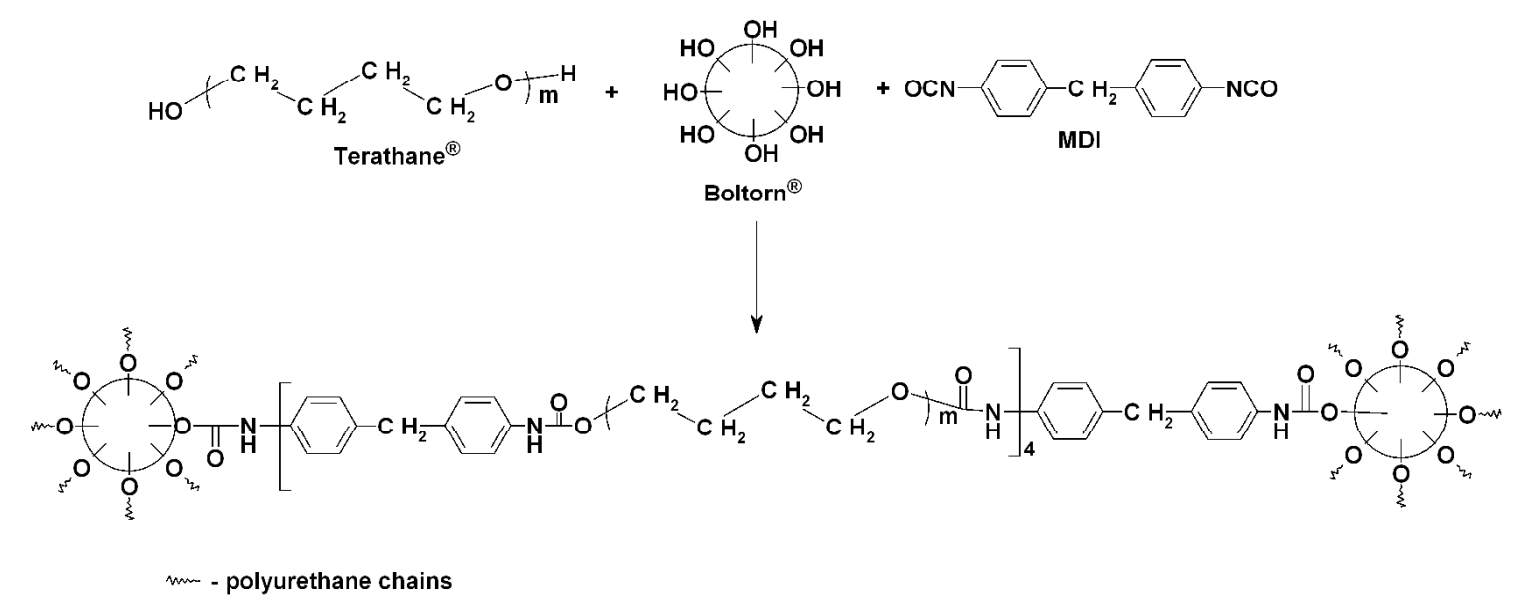

\section{Figure 3}

(a)

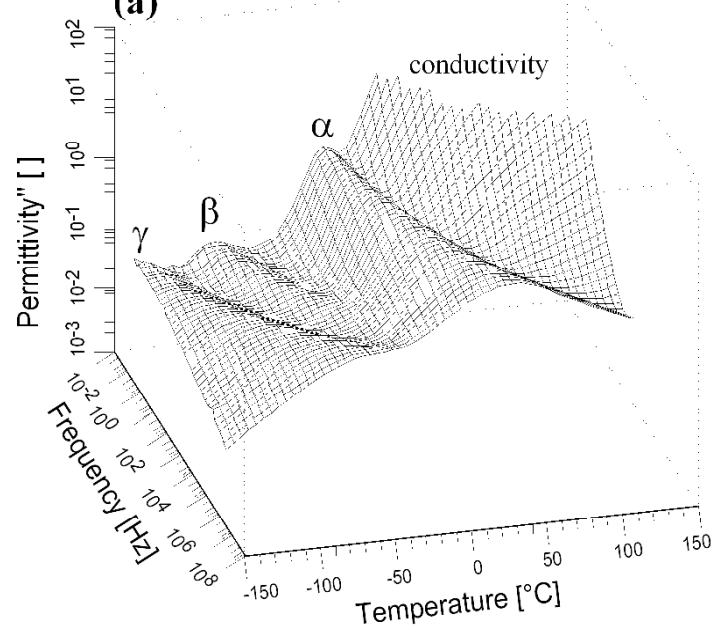

(b)

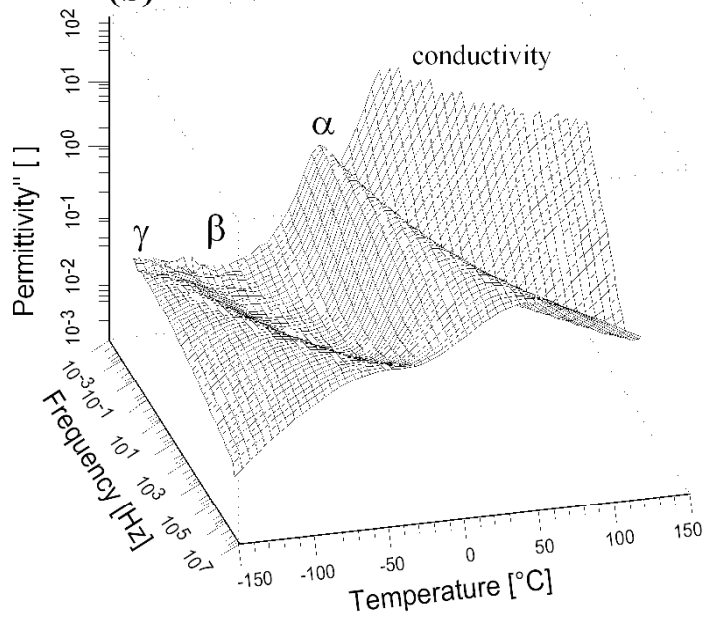

\section{Figure 4}



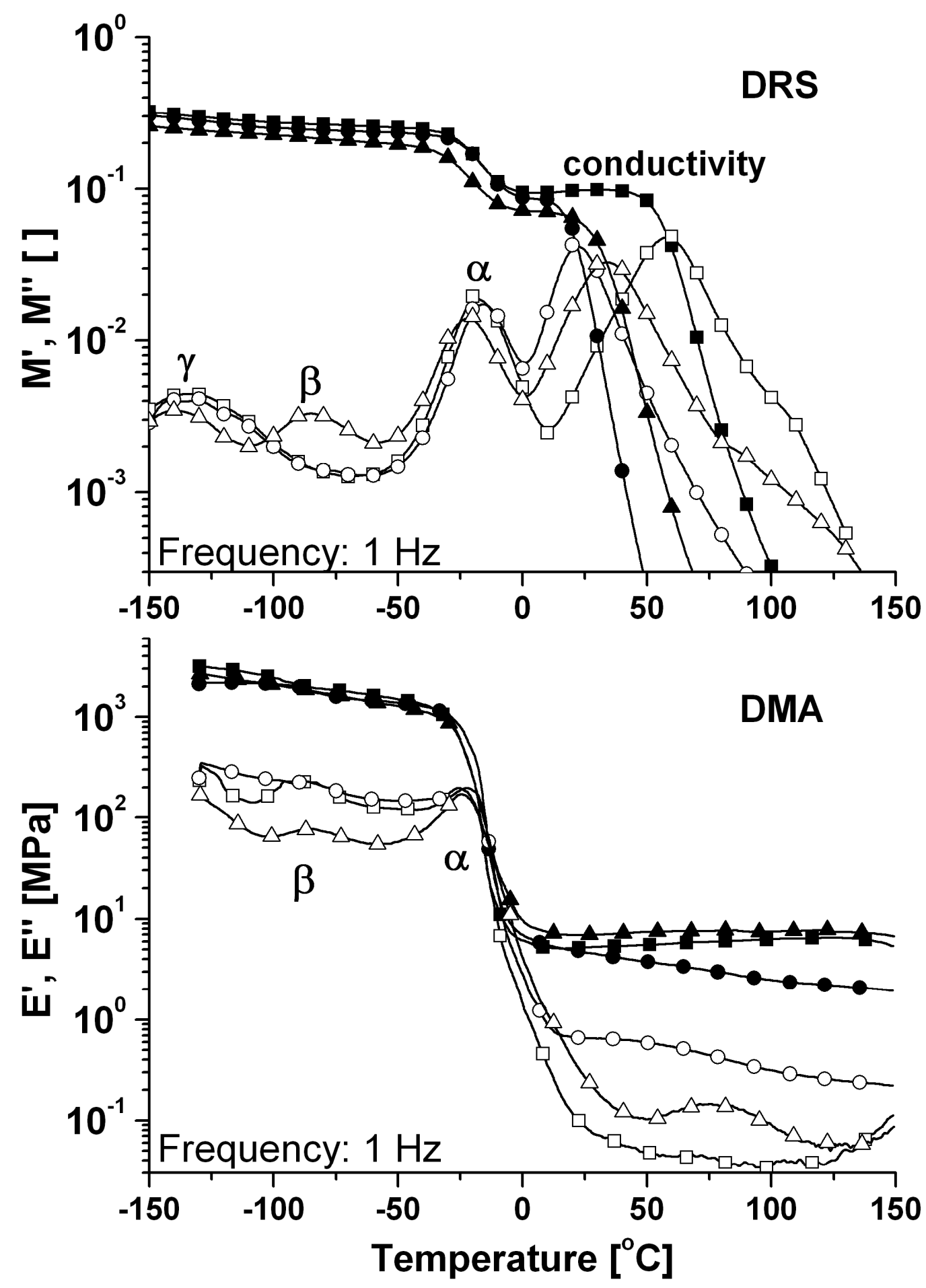

Figure 5 


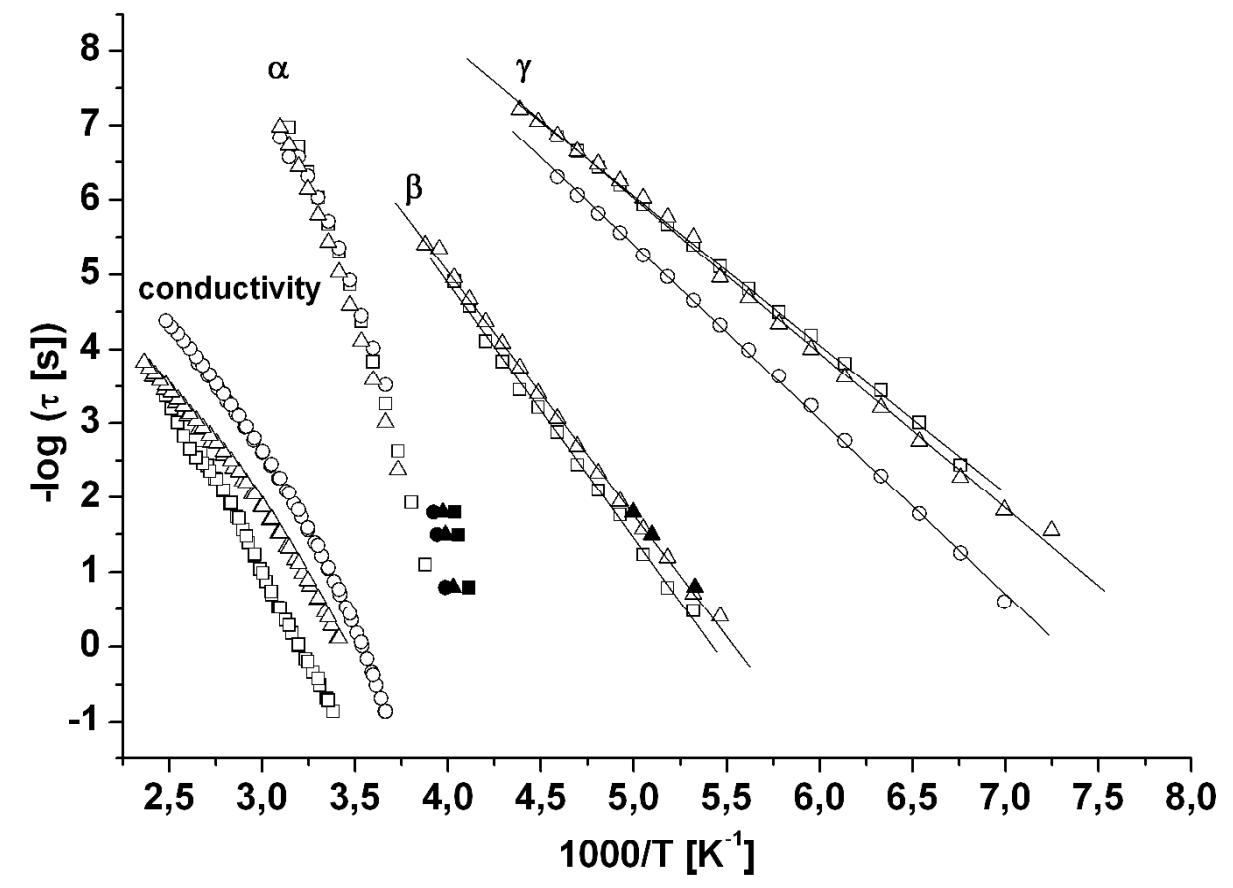

Figure 6

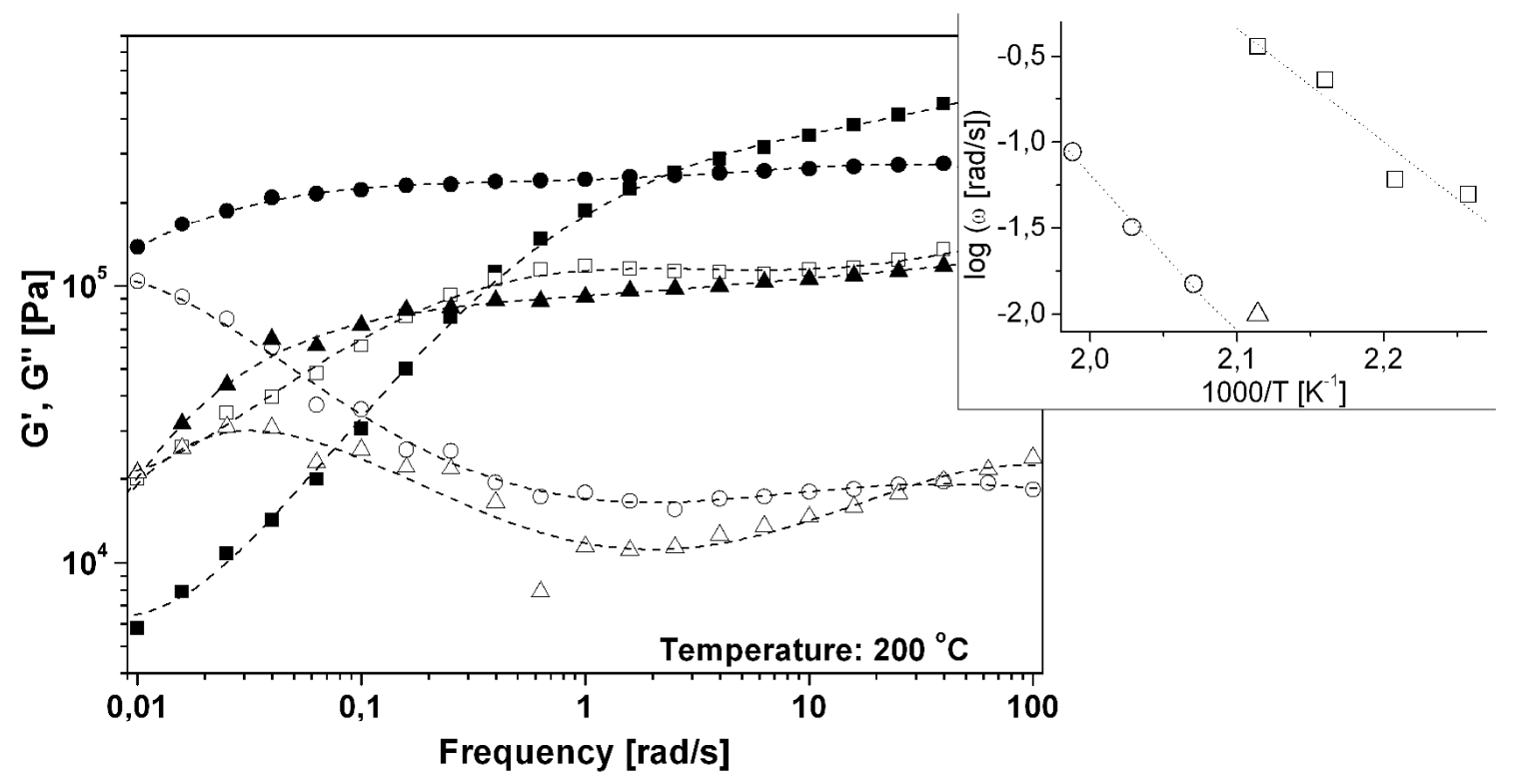

Figure 7 


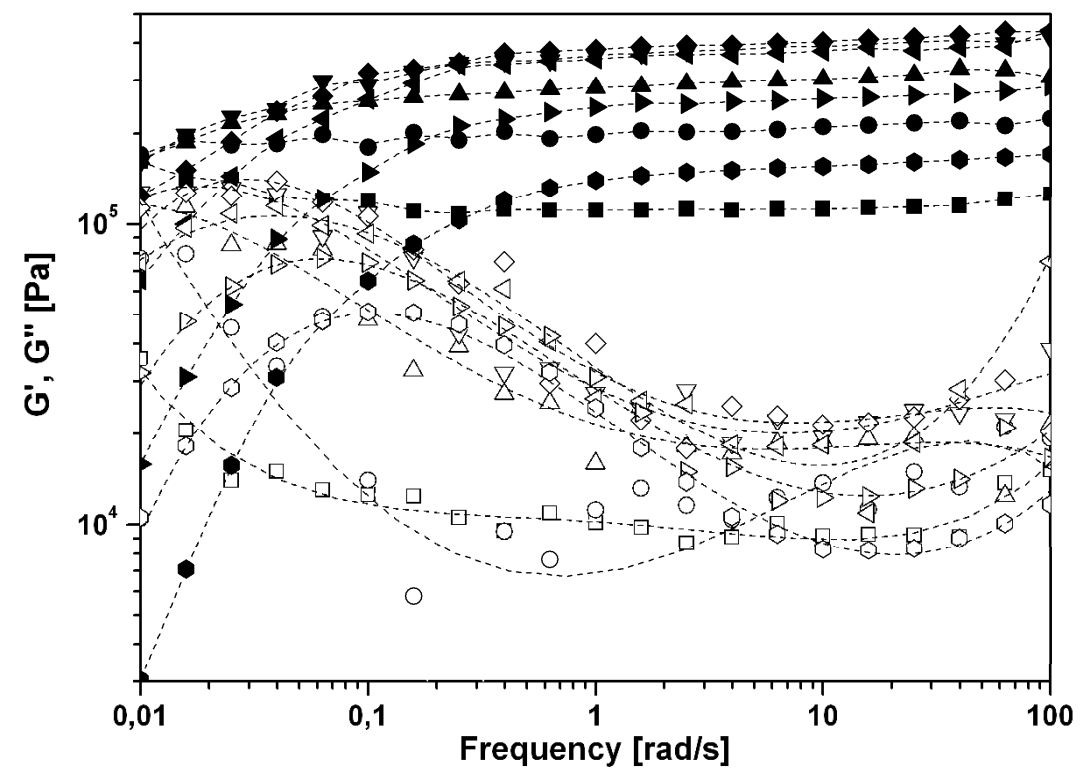

Figure 8 


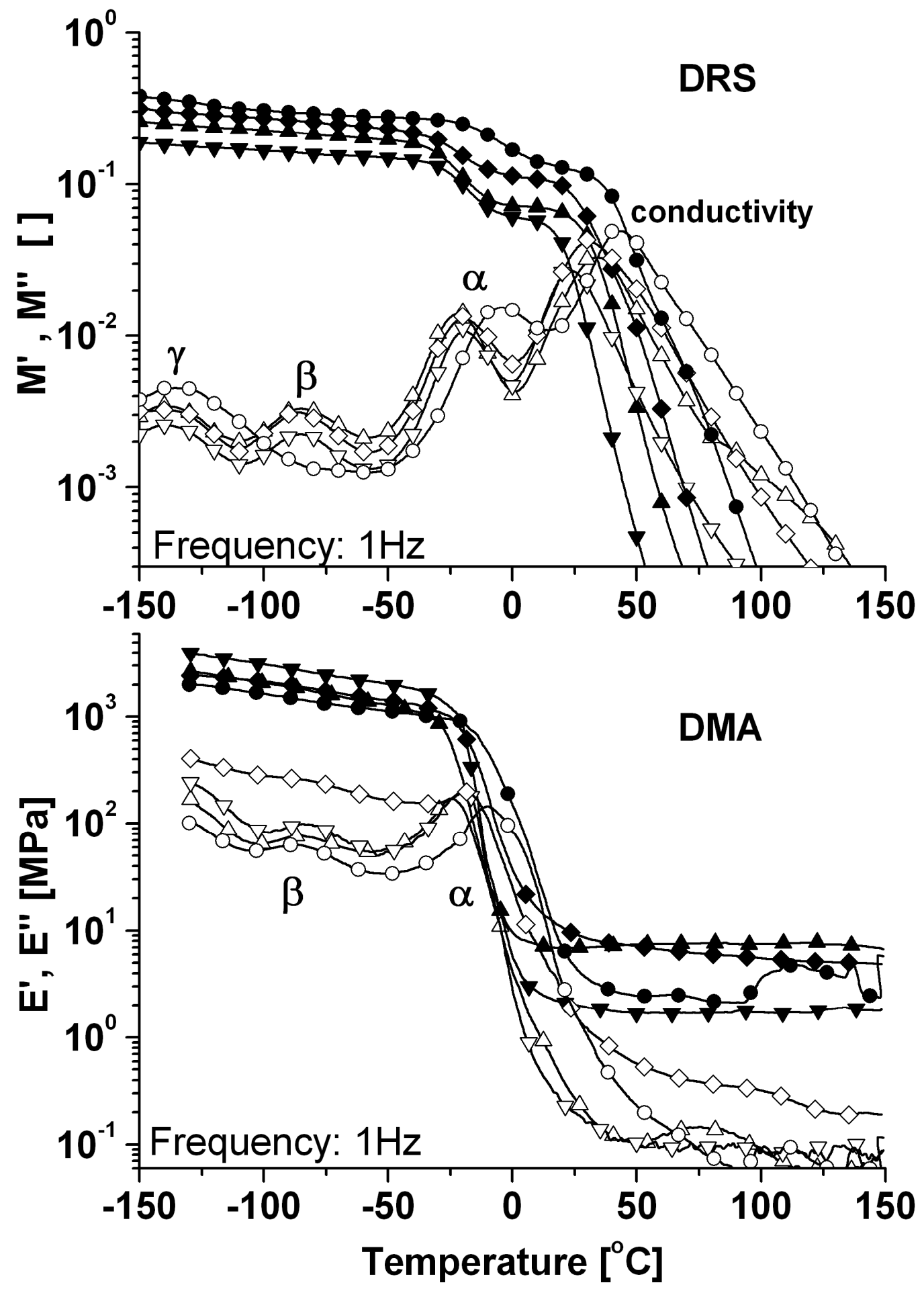

Figure 9 


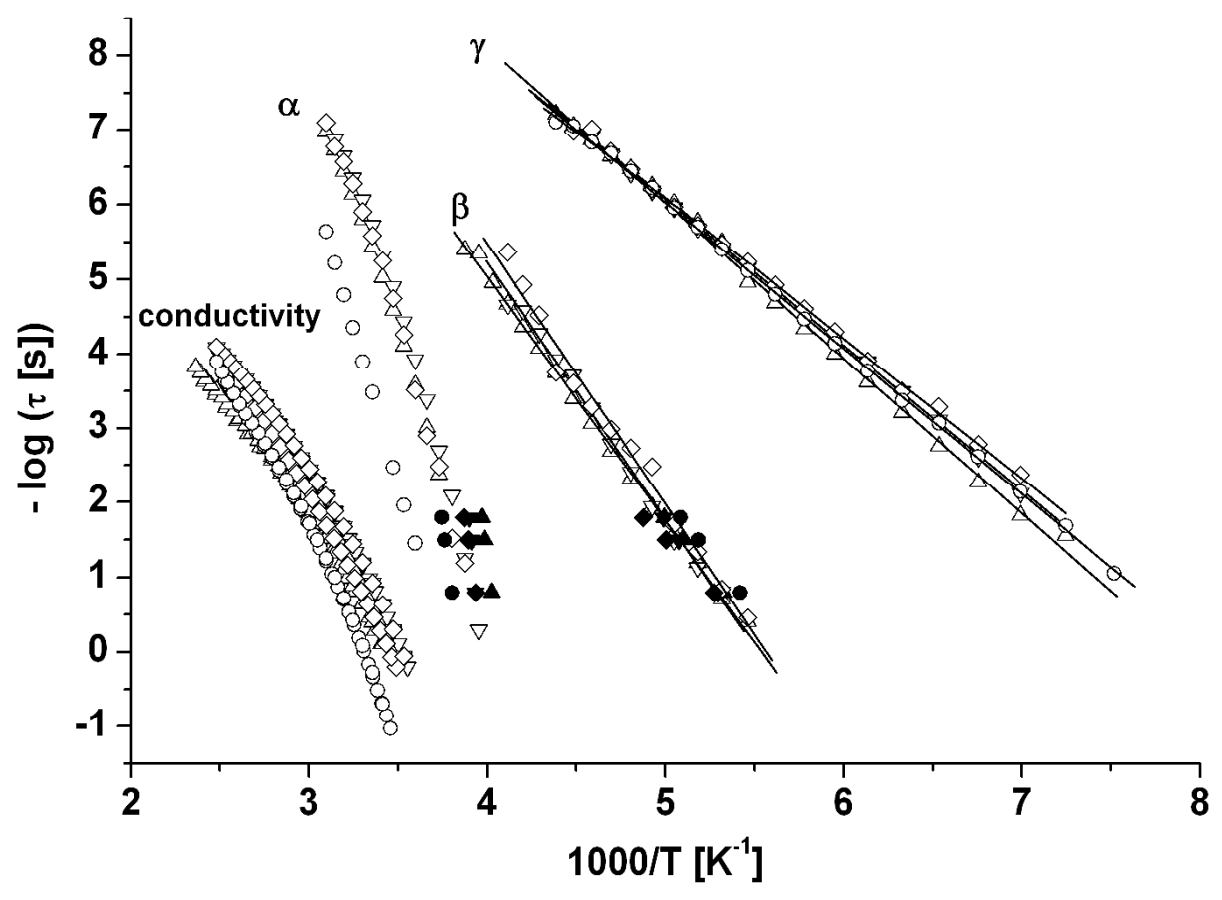

Figure 10

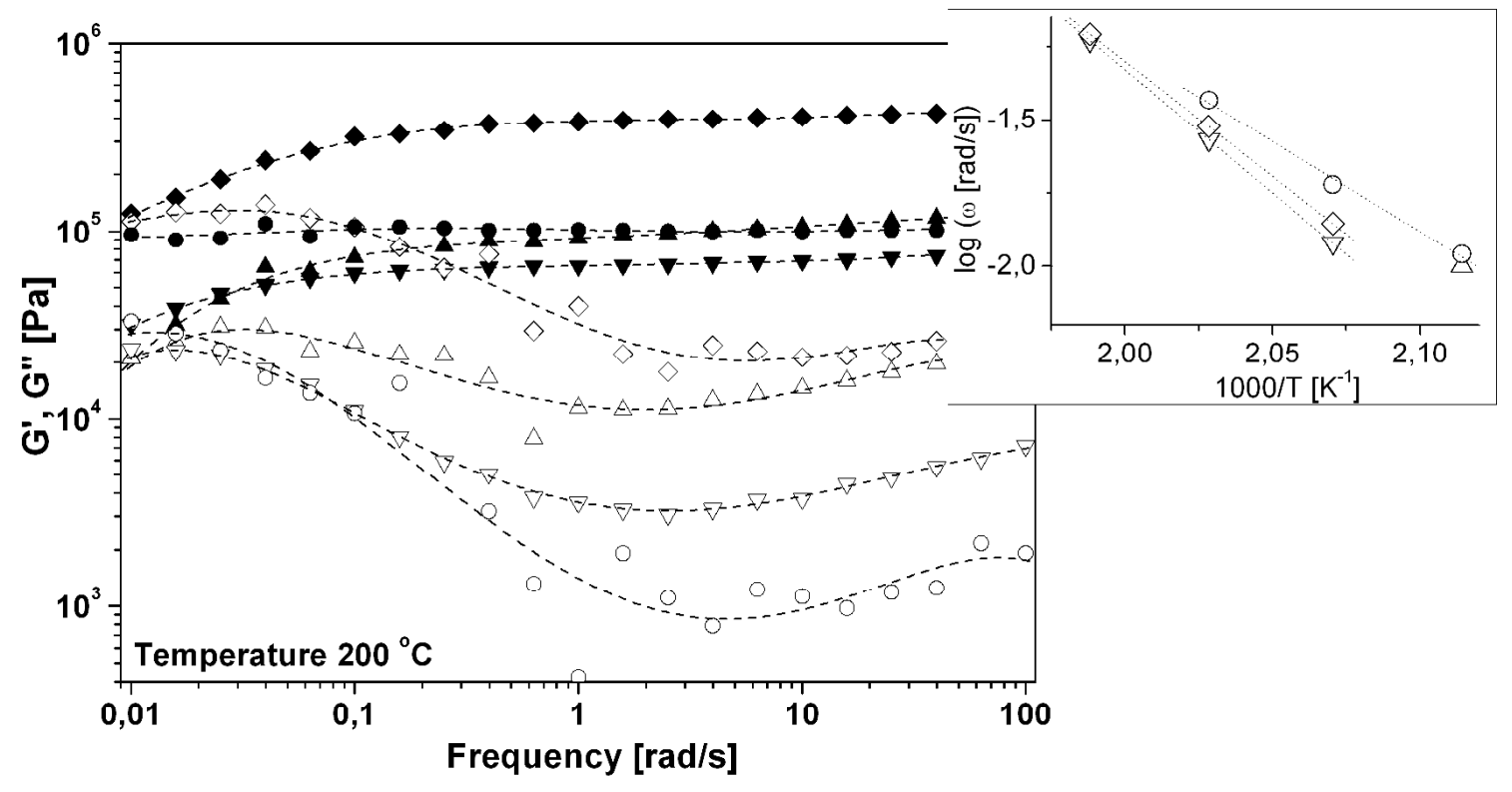

Figure 11 


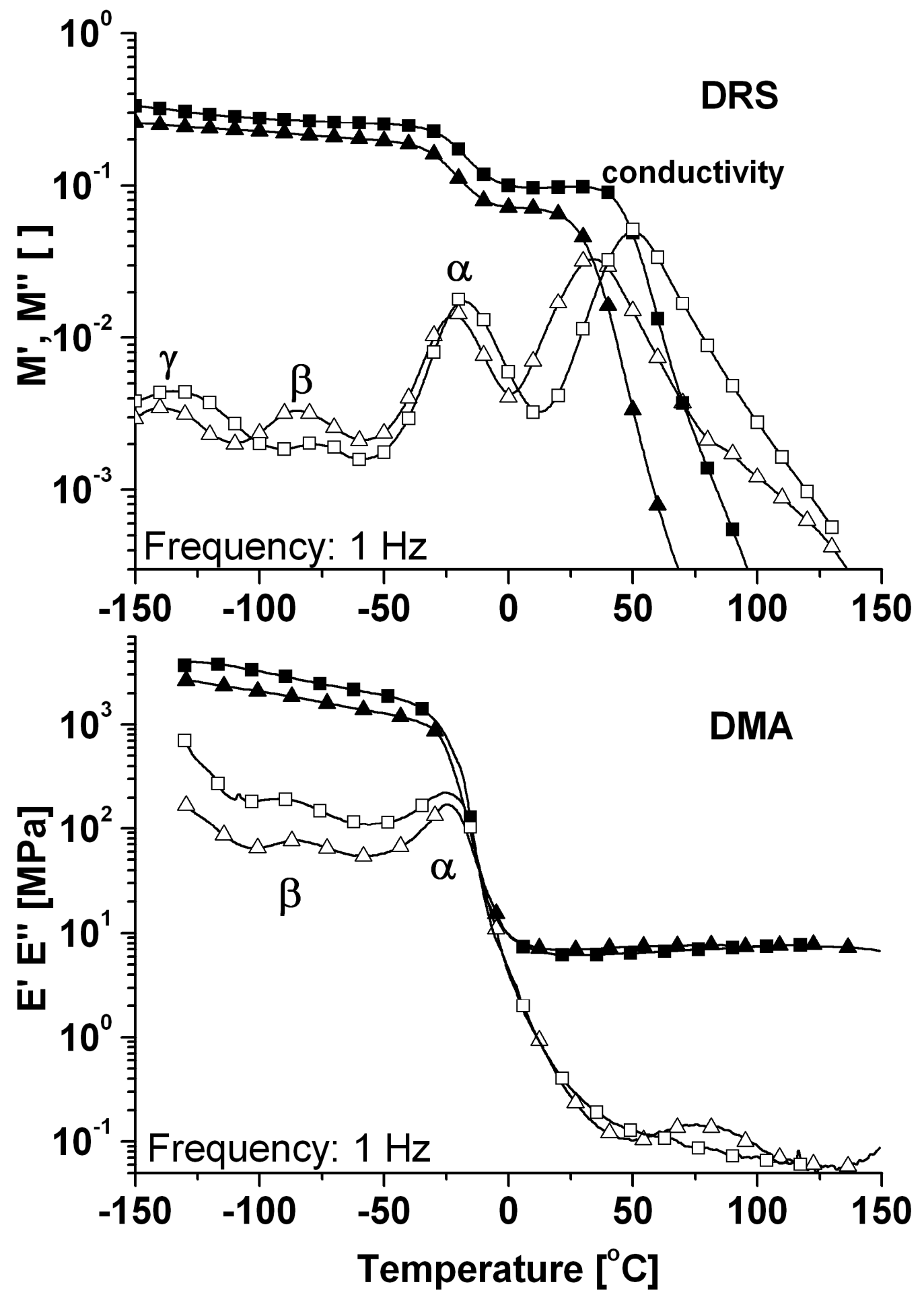

Figure 12 


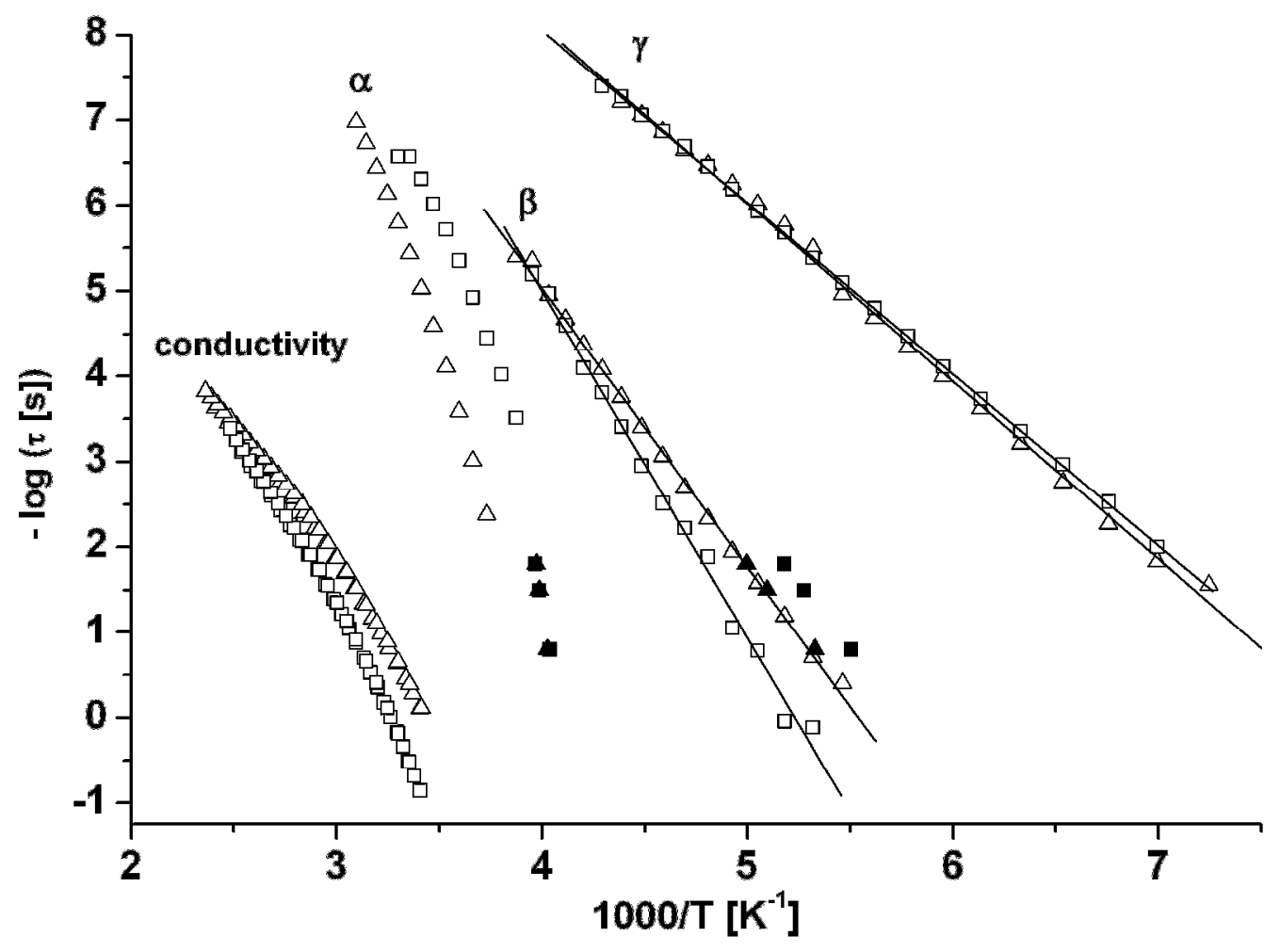

Figure 13

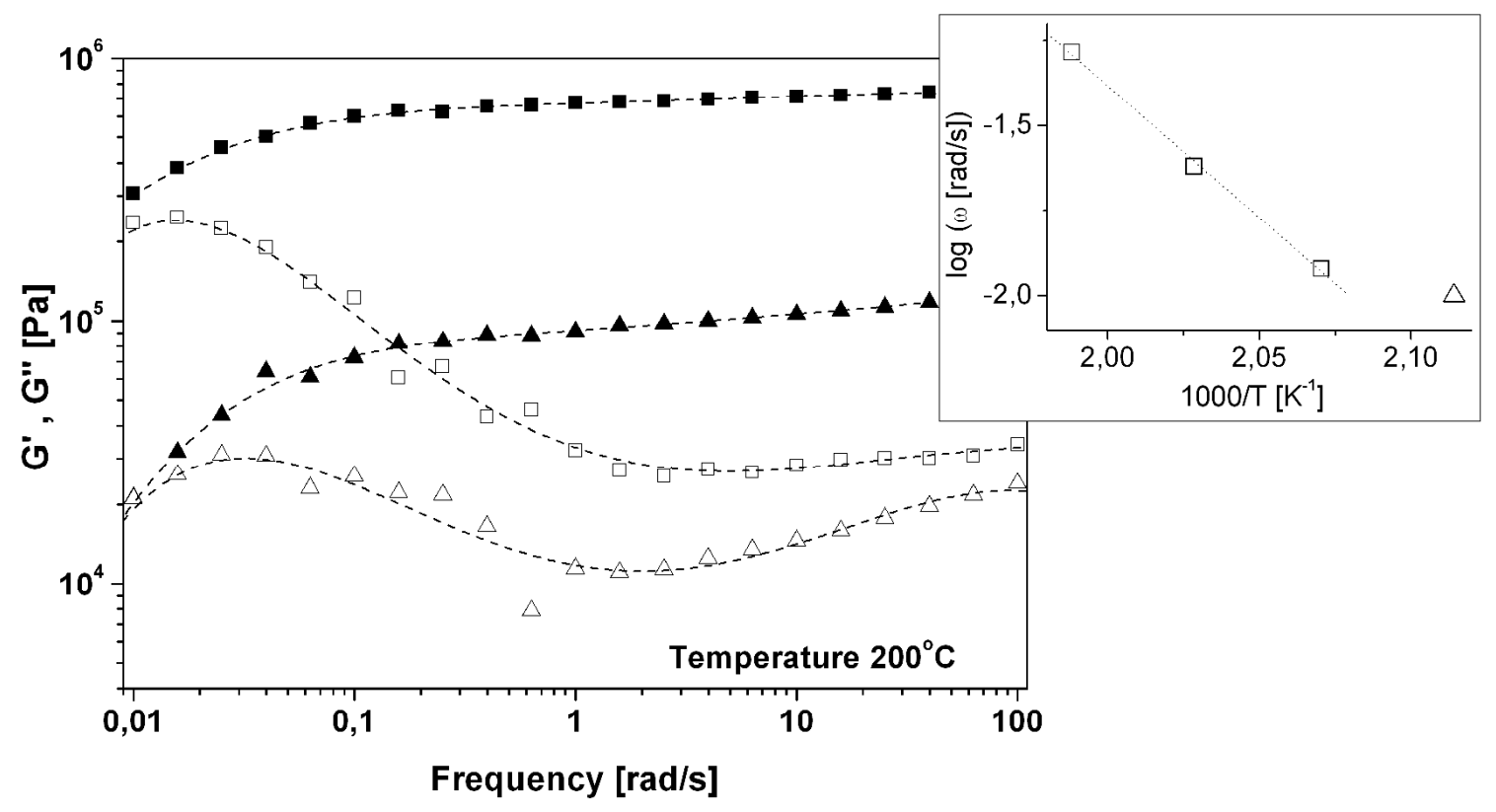

Figure 14 